\title{
Effects of Fenugreek (Trigonella foenum-graecum L.) Seed Powder on Growth Performance, Visceral Organ Weight, Serum Cholesterol Levels and the Nitrogen Retention of Broiler Chicken
}

\author{
A.S. Weerasingha and N.S.B.M. Atapattu* \\ Department of Animal Science \\ Faculty of Agriculture, University of Ruhuna \\ Mapalana, Kamburupitiya, Sri Lanka
}

\begin{abstract}
Fenugreek (Trigonella foenum-graecum L.) is a medicinal plant having a range of therapeutic, anti-microbial and growth promoting effects. Objective of this study was to evaluate the effects of fenugreek seed powder on growth performance, visceral organ weight, serum cholesterol levels and the nitrogen (N) retention of broiler chicken. In a Complete Randomized Design with six replicates, 108 chicks in 36 pens received one of the six experimental diets containing either 0, 1, 2, 3, 4, $5 \%$ fenugreek powder from day 21-38. The weight gain of the birds that were fed with 4 and $5 \%$ fenugreek was significantly lower $(p<0.05)$ than that of the birds fed with $1 \%$ fenugreek powder. One percent fenugreek powder improved the feed conversion ratio (FCR) by $13.8 \%$, compared to birds in the control group. Dietary fenugreek linearly increased the relative length of the small intestine and the weight of the pancreas. The $N$ retention and serum cholesterol level were not significantly $(p>0.05)$ altered by dietary fenugreek. It was concluded that $1 \%$ dietary fenugreek has some growth promoting effects in broiler chicken.
\end{abstract}

Keywords: Broiler, cholesterol, Fenugreek, growth, pancreas

\section{INTRODUCTION}

Phytogenic feed additives are plant-derived products used in animal feeding to improve the performance of agricultural livestock (Windisch et al., 2008). Herbs, spices, and various plant extracts have received increased attention as possible alternatives to antibiotic growth promotants (AGP), since they are considered natural products (Henandez et al., 2004). Griggs and Jacob, (2005) and Windisch et al. (2008) reviewed the antimicrobial and growth promotant effects of a range of phytogenic feed additives including thyme (Thymus vulgaris), clove (Syzygium aromaticum), turmeric (Curcuma longa), black pepper (piper nigram), oregano (Oregano vulgar), garlic (Alum sativa) and fenugreek (Trigonella foenum graecum).

Seeds of Fenugreek (Trigonella foenum-graecum L.) is reported to have many therapeutic effects such as hypoglycemic, hypocholesterolaemic, anthelmintic, antibacterial, antiinflammatory, antipyretic and antimicrobial properties (Bash et al., 2003; Safaa, 2007). Fenugreek seeds contain neurin, biotin and trimethylamine which tend to stimulate the appetite by their action on the nervous system (Al Habori and Roman, 2002). Alloui et al. (2012) reported that $0.3 \%$ fenugreek had positive effects on growth performance of broiler

* Corresponding author: mahindaatapattu2gmail.com 
chick where as Abbas (2010) found negative effects on feed intake and no effect on live weight. Apart from a range of beneficial effects including growth promoting, having $24 \%$ $\mathrm{CP}$ and 3819 (ME) Kcal/Kg of energy and rich in vitamins and minerals, fenugreek can be regarded as a nutritious feed ingredient as well. El-Mallah et al. (2005) reported that $2 \%$ fenugreek in diets of turkey chicks significantly increased the digestibility of nitrogen free extract due to saponin present in fenugreek. Meanwhile, Al-Habori et al. (1998) found that fenugreek reduced the plasma cholesterol levels of rabbit.

Objective of this study was to determine the effects of a range of dietary fenugreek seed powder on growth performance, serum cholesterol, HDL, LDL levels and visceral organ weights of broiler chicken.

\section{METHODOLOGY}

Day old broiler chicks were brooded on an electrically heated floor brooder for ten days. Until day 20, chicks were fed a commercial broiler starter diet. On day 20, chicks $(\mathrm{n}=108)$ were weighed and allocated into 36 pens $(0.75 \mathrm{~m} \times 0.75 \mathrm{~m} \times 0.75 \mathrm{~m})$ so that live weight variation among the pens was minimum. Each Pen had a drinker, a feeder and paddy husk as the litter material. The experiment followed a completely randomize design with six replicate pens, each having three birds. Pens were randomly allocated into six dietary treatments. Except for energy and methionine+cystine, the basal diet with $0 \%$ fenugreek seed powder met the nutrient requirements as set out by NRC (1994) (Table 1). Other five experimental diets were prepared by mixing either 1,2, 3, 4 or $5 \%$ fenugreek seed powder with basal diet. Fenugreek seeds were purchased from a local market and ground before being incorporated into the experimental diets. The experimental diets and water were given ad libitum from day 21-38.

On day 33, birds were transferred to raised wire-floors fixed to the same cages. A total collection of feces was done for three days (from day 35-37), after two days of acclimatization period. $\mathrm{N}$ retention was determined as described by Leeson and Zubair, (1997). Blood was collected from wing vain of one randomly selected bird from each pen, on day 33. Blood sugar, serum cholesterol, LDL, HDL and total triglyceride were determined using commercial assay kits (SPINREACT, S.A. Ctra, Santa Coloma, Spain). One randomly selected bird from each pen was sacrificed on day 38 and visceral organ weights were determined. Small intestine was determined as the length from gizzardduodenum junction to ileo-caeco-colic junction. Visceral organ weighs were expressed as a percentage of de-skinned empty carcass.

Data were analyzed using SAS (1989), as a completely randomize design experiment. Pen means served as replicates in the analysis of growth performance parameters while randomly selected birds were the replicates of carcass and blood parameter analysis. Means were compared using DMRT procedure. 
Table 1. Ingredient and nutrient composition of the basal diet

\begin{tabular}{lc}
\hline \multicolumn{1}{c}{ Ingredient } & \% \\
\hline Maize meal & 56.8 \\
Soybean meal & 37 \\
Coconut oil & 3 \\
Dicalcium phosphate & 1.2 \\
Shell powder & 1.5 \\
Salt & 0.25 \\
Vitamin mineral mixture & 0.25 \\
Nutrient composition (Calculated) & \\
Energy (ME Kcal/kg) & \\
Crude protein (\%) & $19.9^{*}$ \\
Calcium (\%) & 0.9 \\
Non phytate phosphorus (\%) & 0.35 \\
Lysine (\%) & 1.1 \\
Methionine + Cystine (\%) & 0.67 \\
Crude fibre (\%) & 4 \\
\hline
\end{tabular}

*Analyzed

\section{RESULTS AND DISCUSSION}

Contrary to a number of studies (Abaza, 2007; Alloui 2012; Awadein et. al., 2010: Alloui et al., 2012; Abaza, 2007; Alloui et al., 2012) fenugreek did not significantly improve the feed intake or live weight (Table 2). Instead, $5 \%$ fenugreek tend to reduce the live weight on day $38(\mathrm{p}=0.054)$ and feed intake ( $\mathrm{p}=0.06)$. Abaza, (2007) and Awadein et. al. (2010) also indicated that the $0.5 \%$ fenugreek seeds decreased the feed consumption in laying hens. It is noted that all the studies in which fenugreek produced positive effects on growth performance have used lower inclusion levels than what used in this experiment. Therefore, it is hypothesized the optimum level of dietary fenugreek that induces positive effects on growth performance is lower than $1 \%$. Comparable or sometimes superior performance of birds fed $1 \%$ fenugreek over the control birds further support this assumption. 
Table 2. Effects of dietary fenugreek powder on growth performance, serum cholesterol levels and $\mathrm{N}$ retention of broiler chicken from 21-38 days

\begin{tabular}{|c|c|c|c|c|c|c|c|c|}
\hline \multirow[b]{2}{*}{ Parameter } & \multicolumn{6}{|c|}{ Level of dietary fenugreek (\%) } & \multirow{2}{*}{$\begin{array}{l}\text { Pooled } \\
\text { SEM }\end{array}$} & \multirow[t]{2}{*}{ P value } \\
\hline & 0 & 1 & 2 & 3 & 4 & 5 & & \\
\hline $21 \mathrm{~d}$ & 623 & 614 & 614 & 607 & 617 & 618 & 13 & 0.55 \\
\hline $38 \mathrm{~d}$ & 1776 & 1831 & 1741 & 1731 & 1599 & 1560 & 164 & 0.054 \\
\hline Weight gain $(g)$ & $1152^{\text {ba }}$ & $1216^{\mathrm{a}}$ & $1127^{\text {ba }}$ & $1123^{\text {ba }}$ & $982^{\mathrm{b}}$ & $941^{\mathrm{b}}$ & 163 & 0.04 \\
\hline Feed intake $(\mathrm{g})$ & 2640 & 2629 & 2589 & 2518 & 2437 & 2412 & 152 & 0.06 \\
\hline FCR & 2.52 & 2.17 & 2.36 & 2.25 & 2.54 & 2.58 & 0.39 & 0.46 \\
\hline \multicolumn{9}{|c|}{ Blood parameters (mg/dl) } \\
\hline Sugar & 215 & 202 & 222 & 205 & 207 & 221 & 17 & 0.47 \\
\hline Cholesterol & 149 & 149 & 150 & 153 & 131 & 138 & 18 & 0.37 \\
\hline HDL & 67 & 66 & 69 & 68 & 57 & 61 & 11 & 0.55 \\
\hline LDL & 58 & 56 & 55 & 60 & 48 & 49 & 8.6 & 0.10 \\
\hline Triglyceride & 115 & 128 & 123 & 123 & 128 & 137 & 13 & 0.21 \\
\hline Ratio & 2.2 & 2.28 & 2.19 & 2.26 & 2.31 & 2.26 & 0.15 & 0.87 \\
\hline $\begin{array}{l}N \text { retention } \\
*_{\mathrm{g} / 100 \text { body weight) }}\end{array}$ & 0.48 & 0.55 & 0.53 & 0.56 & 0.57 & 0.60 & 0.06 & 0.08 \\
\hline
\end{tabular}

Weight gain of the birds given 1\% fenugreek was significantly higher than that of 4 and $5 \%$ fenugreek fed counterparts. Though there were no significant differences in live weight on day 38, weight gain and FCR between the broilers given 0 and $1 \%$ fenugreek, the latter group reported the highest live weight and weight gain. Furthermore, giving a $13.8 \%$ improvement compared to control group, the birds fed $1 \%$ fenugreek reported the best FCR. Above findings suggest that $1 \%$ dietary fenugreek has some growth promoting effect in broilers.

The empty carcass weight of the broilers given control and $1 \%$ fenugreek was also significantly higher than those fed 3, 4 or $5 \%$ fenugreek fed birds (Table 3). The relative length of the small intestine was significantly higher for birds given 2,4 or $5 \%$ fenugreek than those fed 0 or $1 \%$ fenugreek. There was a significant linear increase in relative length of the small intestine with increasing dietary fenugreek levels; $\mathrm{y}=13.2+1.11 \mathrm{x}$ dietary fenugreek \%. It is suggested that, though fenugreek has negative effects on growth in general, the growth of the intestine has not been retarded. The findings of Govaerts et al. (2000) and Susbilla et al. (1994) that growth of supply organs such as stomach and intestine receives priority in nutrient partitioning within the body support the above hypothesis. 
Effects of Fenugreek (Trigonella foenum-graecum L.) on Broiler Chicken

Table 3. Effects of dietary fenugreek seed powder on visceral organ weights of broiler chicken

\begin{tabular}{|c|c|c|c|c|c|c|c|c|}
\hline \multirow[t]{2}{*}{ Organ } & \multicolumn{6}{|c|}{ Dietary fenugreek level (\%) } & \multirow[t]{2}{*}{ SEM } & \multirow{2}{*}{$\begin{array}{c}P \\
\text { value }\end{array}$} \\
\hline & 0 & 1 & 2 & $\mathbf{3}$ & 4 & 5 & & \\
\hline${ }^{1}$ Empty carcass & $1296^{\mathrm{a}}$ & $1273^{\mathrm{a}}$ & $1165^{\text {ba }}$ & $1104^{b c}$ & $1068^{\mathrm{bc}}$ & $975^{\mathrm{c}}$ & 16 & 0.002 \\
\hline Crop & 0.41 & 0.46 & 0.60 & 0.37 & 0.38 & 0.46 & 0.02 & 0.50 \\
\hline Proventriculus & 0.55 & 0.70 & 0.70 & 0.73 & 0.75 & 0.79 & 0.32 & 0.34 \\
\hline Gizzard & 2.87 & 3.02 & 2.81 & 3.05 & 3.3 & 3.02 & 0.06 & 0.43 \\
\hline $\begin{array}{l}{ }^{2} \text { Small intestine } \\
\text { (length) } \mathrm{cm} / 100 \mathrm{~g} \mathrm{BW}\end{array}$ & $13.8^{\mathrm{b}}$ & $13.9^{\mathrm{b}}$ & $14.3^{\mathrm{b}}$ & $17.0^{\mathrm{a}}$ & $17.3^{\mathrm{a}}$ & $19.0^{\mathrm{a}}$ & 0.24 & 0.001 \\
\hline Liver & 4.4 & 3.3 & 2.9 & 3.2 & 3.3 & 3.7 & 0.11 & 0.12 \\
\hline Pancreas & $0.32^{\mathrm{b}}$ & $0.28^{\mathrm{b}}$ & $0.37^{\mathrm{b}}$ & $0.43^{\mathrm{b}}$ & $0.46^{\mathrm{b}}$ & $0.70^{\mathrm{a}}$ & 0.0 .02 & 0.000 \\
\hline Spleen & 0.23 & 0.26 & 0.25 & 0.32 & 0.17 & 0.19 & 0.01 & 0.41 \\
\hline Cloacal fat & 1.53 & 1.42 & 1.34 & 1.67 & 1.14 & 1.74 & 0.10 & 0.76 \\
\hline Bursa & 0.27 & 0.30 & 0.28 & 0.28 & 0.14 & 0.20 & 0.05 & 0.22 \\
\hline Heart & 0.72 & 0.70 & 0.79 & 0.69 & 0.74 & 0.87 & 0.05 & 0.51 \\
\hline
\end{tabular}

Meanwhile, the relative weight of the pancreas of the birds fed 5\% dietary fenugreek was significantly higher than other groups. There was a significant linear increase of relative pancreas weight with increasing dietary fenugreek levels; $\mathrm{y}=0.250+0.0715 \mathrm{x}$ dietary fenugreek level. Perilla et al. (1997) and Chohan et al. (1993) have shown that pancreas become hypertropic to compensate the negative effects of anti-proteolytic substances on protein digestibility resulting in an increased relative weight of the pancreas. Gacche et al. (2010) reported moderate level of anti-proteolytic activity in fenugreek. Suggesting that pancreatic hypertrophy compensated the negative effects of anti-proteolytic substances, the $\mathrm{N}$ retention was not reduced by higher dietary fenugreek levels (Table 2). Trypsin inhibitors reduced the feed intake of broilers (Carmen et al., 1999; Chohan et al., 1993) and thus reduced feed intake of the birds fed fenugreek may be due to the anti-proteolytic substances. Even though fenugreek contain as high as $24 \% \mathrm{CP}$ and $3800 \mathrm{Kcal} \mathrm{ME} / \mathrm{Kg}$ (Abbas, 2010), the use of it at higher levels as a feed ingredient of poultry feed formulations may be limited due to the presence of anti-proteolytic substances. Relative weights of the crop, proventriculus, gizzard, heart, spleen, bursa of fabricious and the cloacal fat contents were not significantly altered due dietary fenugreek. Abbas, (2010) and Abaza, (2007) have also reported similar results.

A number of studies (Abbas, 2010; Abdel-Rasoul and Yousif, 2003; El-Ghamry et al., 2002) have shown that serum cholesterol levels were reduced when fenugreek was added. However, none of the serum parameters including serum cholesterol was significantly reduced due to fenugreek levels used in this experiment. 


\section{CONCLUSIONS}

It is concluded that $1 \%$ dietary fenugreek seed powder has some growth promoting effects in broilers. Higher than $1 \%$ dietary fenugreek has negative effects on feed intake and growth performance. Dietary fenugreek increases the relative length of the small intestine and the weight of the pancreas. Serum cholesterol levels are not affected by the dietary fenugreek.

\section{ACKNOWLADGMENT}

Mr. P.K. Lal and M.M.K. Premakumara are acknowledged for their technical assistance.

\section{REFERENCES}

Abaza, I.M. (2007). Effects of using fenugreek, camomile and radish as feed additives on productive performance and digestibility coefficients of laying hens. Poult. Sci. 27, 199-218.

Abbas, R.J (2010). Effect of using fenugreek, parsley and sweet basil seeds as feed additives on the performance of broiler chickens. Int. J. Poult. Sci. 9, 278-282

Abdel-Rasoul, E.M. and Yousif, W.H. (2003). Effect of fenugreek (Trigonella FoenumGraecum) seeds powder (as capsules) on certain physiological aspects of broiler chicken treated with vanadyl sulphate. Iraqi J. Vet. Sci. 17, 101-109.

Al-Habori, M., Al-Aghbari, A.M. and Al-Mamary, M. (1998). Effect of fenugreek seeds and its extracts on plasma lipid profile: A study on rabbits. Phytotherapy. Res. 12, 572-575.

Al-Habori, M. and Roman, A. (2002). Pharmacological properties in fenugreek- The genus Trigonella. Pp. 163-182. In: Petropoulos, G.A. (Ed.). Taylor and Francis, London and New York.

Alloui, N., Ben, S., Alloui, M.N. and Ibrir, F. (2012). Utilization of fenugreek (Trigonella foenum-graecum) as growth promoter for broiler chickens. J. World's Poult. Res. 2, 25-27.

Awadein, B.N., Enid, Z.Y. and El-Ghana, A.F. (2010). Effect of dietary supplementation with phytoestrogens sources before sexual maturity on productive performance of mandarah hens. Egypt. Poult. Sci. 30, 829-846.

Bash, E., Ulbricht, C., Kuo, G., Szapary, P. and Smith. M. (2003). Therapeutic applications of fenugreek. Alt. Med. Rev. 8, 20-27.

Carmen, J.D., Gernat, A.G., Myhrman, R. and Carew, L.B. (1999). Evaluation of raw and heated velvet beans (Mucuna pruriens) as feed ingredients for broilers. Poult. Sci. 78, 866872.

Chohan, A., McNiven, M.K., Hamilton, R.M.G. and. MacLeod, J.A. (1993). High protein and low trypsin inhibitor varieties of full-fat soybeans in broiler chicken starter diets. J. Anim. Sci. 73, 401-409. 
El-Ghamry, A.A., Azouz, H.M. and. El-Yamany, A.M. (2002). Effect of hot pepper and fenugreek seeds supplementation to low energy diets on Muscovi ducklings performance. Egypt. Poult. Sci. 24, 613- 627.

El-Mallah, G.M., Ibrahim, S.A. M. and. Abdo, M.A.Z. (2005). Garlic and fenugreek as feed additives to different levels of protein and energy in diets of growing turkeys. Egypt. Poult. Sci. 25, 911-929.

Gacche, R.N., Dhole, N.A., Jadhav, A.D. (2010). Free radical scavenging activity, antioxidative ingredients, and possible anti-inflammatory abilities of selected traditional medicinal plants from ayurveda. J. Nat. Rems. 10, 64-73.

Govaerts, T., Room, G., Buyse, J., Lippens, M., De Groote, D. and, Decuypere, E (2000). Early and temporary quantitative food restriction of broiler chickens. Effects on allometric growth and growth hormone secretion. Brit. Poult. Sci. 41, 355-362.

Griggs, J.P. and Jacob, J.P. (2005). Alternatives to antibiotics for organic poultry production. J. Appl. Poul. Res. 14, 750-756.

Henandez, F., Mardrid, J., Garcia, V., Orengo, J. and Megias, M.D. (2004). Influence of two plant extracts on broiler performance, digestibility, and digestive organ size. Poult. Sci. 83, 169-174.

Leeson, S. and. Zubair. A.K. (1997). Nutrition of the broiler chicken around the period of compensatory growth. Poult. Sci. 76, 992-999.

National Research Council (1994). Nutrient requirements of poultry. $9^{\text {th }}$, rev. ed., National Academy press. Washington, DC.

Perilla, N.S., Cruz, M.P., De Belalcazar, F.D. and Diaz, G.J. (1997). Effect of temperature and wet extrusion on the nutritive value of full-fat soybeans for broiler chickens. Brit. Poult. Sci. $38,412-416$.

Safaa, H.M. (2007). Effect of dietary garlic or fenugreek on cholesterol metabolism in laying hens. Egypt Poult. Sci. 27, 1207-1221.

SAS (1989). SAS/STAT user's Guide Release 6.4 Edition, SAS Institute Inc., cary, NC, USA.

Susbilla, J.P., Frankel., T.L., Parkinson, G. and Gow, C.B. (1994). Weight of internal organs and carcass yield of early food restricted broilers. Brit. Poult. Sci. 35, 677-685.

Windisch, W., Schedle, K., Plitzner, C. and Kroismayr, L. (2008) Use of phytogenic products as feed additives for swine and poultry. J. Anim. Sci. 2008. 86(E. Suppl.):E140E148. 